\title{
Improvement of Preventive Maintenance Process Effectiveness in Insourcing and Outsourcing Scheme with House of Risk (HOR) Method Approach (A Case Study)
}

\author{
Budi Siswanto ${ }^{1}$, Adithya Sudiarno ${ }^{2}$, Putu Dana Karningsih², and Henry Pariaman ${ }^{1}$
}

\begin{abstract}
Outsourcing has become the alternative scheme to gain improvement in several fields within a short time to many enterprises. One power generation in North Java implemented PM as planned maintenance strategy to maintain equipment by conducting insourcing and outsourcing scheme as PM execution. Both conditions must follow the same business process flow in PM execution process and there will occur some obstacles that interrupted PM process. The existing problem will be analyzed with House of Risk (HOR) method approach, supported by Integrated Manufacturing Open Systems Architecture (CIMOSA) process-based function modeling for identification method and Supply Chain Risk Identification System (SCRIS) risk structure identification used for mapping problem, root cause, and its relation. Analysis with HOR results in root causes that occurred within PM implementation process for both of them commonly has the same problem that is process business acknowledgment, but in outsourcing scheme not exist root cause on culture compliance and work task requirement, because they have a descriptive target to obtain service level agreement fulfillment. On both scheme still need an improving method to monitor and evaluate the PM work for better performance.
\end{abstract}

Keywords-CIMOSA, House Of Risk, Preventive Maintenance, Corrective Maintenance, Power Generation, Risk, Supply Chain Risk Identification System, Total Productive Maintenance.

\section{INTRODUCTION}

$\mathrm{P}$ hysical assets management in coal-fired power plants, could not inseparable from people within it and the knowledge owned by the company. In UK, assets management in the company to invest in maintenance costs around of $12-23 \%$ of total operating cost [1].

Planned maintenance strategies for asset management is Preventive Maintenance (PM), which is a maintenance method to prevent damage by performing maintenance actions after studying equipment failure [2]. PM placed in Total Productive Maintenance (TPM) with contributions to prevent equipment performance from continuous declining [3].In one Coal-fired steam power plant company in north Java, Indonesia already used Computerized Maintenance Management System (CMMS) as a tool for maintenance management including in PM [4]. In this company, PM has very simple tasks, repetitive work with specified time intervals and predetermined durations, but will support the whole production process [5][6] and PM maintenance expected as front lines on maintenance that maintain equipment conditions can operate according to established performance and measured with indicators measurement [7][8], and [9]. One of the performance indicators for PM taken from World Class Maintenance (WCM) standard is a comparison between PM interval and MTBF which it value is $6: 1$ [10]. PM effect cannot be seen directly on the equipment performance at the time after work but in longterm period of equipment operation, thus the problem of soft skill becomes the main issue in PM implementation process [5][9], and [11]. PM for the main equipment performed by insourcing and for the supporting

${ }^{1}$ Budi Siswanto and Henry Pariaman are with Staff of PT. Pembangkitan Jawa Bali, Surabaya, 60231, Indonesia. E-mail: budi.siswanto@ptpjb.com

${ }^{2}$ Adithya Sudiarno and Putu Dana Karningsih are with Department of Industrial Engineering, Institut Teknologi Sepuluh Nopember, Surabaya, 60111, Indonesia. E-mail: adithya_sudiarno@ie.its.ac.id.
TABLE 1 .

ARP AND AMOUNT OF SELECTED ROOT CAUSE

\begin{tabular}{|c|c|c|c|c|}
\hline \multirow{2}{*}{ No } & \multirow{2}{*}{ Description } & \multicolumn{2}{|c|}{ Aggregate Potential Risk (ARP) } & \multirow{2}{*}{$\begin{array}{c}\text { Root } \\
\text { Cause }\end{array}$} \\
\hline & & Cumulative & $80 \%$ Cumm. & \\
\hline 1 & Insourcing & 571.24 & 454.88 & 15 \\
\hline 2 & Outsourcing & 344.42 & 274.86 & 16 \\
\hline
\end{tabular}

equipment performed by outsourcing. Outsourcing scheme allows management to acquire resources that can be immediately used in chain activities with excellent skills and competencies to enhance contribution company sustainable competitive advantage especially for good operation and the right PM [12][13]. Increasing the quality of services can increase revenue for contractor and decrease the total production cost [7][14]. Soft skill is the ability of the individual in improving the interaction and performance of work and is interpersonal and widely applicable, while the hard skills of individual ability to complete a specific job with specific ability demands while the hard skill is more towards the method of how to do the work and soft skill proved to affect the company to create new products or service improvement [15][16][17][18], and [19]. The walk around method will increase the motivation of the employees to further improve the PM work result, as well as can be another side view of management to improve maintenance performance of PM [7][20], and [21]. The problem of soft skills still dominates problem root causes that inhibit PM works and this can be solved with concern in conducting corporate culture, support with respectively management role and providing appropriate monitoring and evaluation system [9].

This study will make a comparison on proactive strategy between PM in compressor system, which used insourcing, and conveyor system, which used outsourcing. Previous research shows that soft skill was the dominant factor that influences on PM effectiveness. In order to make a same analysis on root causes that influence in the process, research data gathering will 
TABLE 2 .

LIST OF SELECTED ARP RoOT CAUSES

\begin{tabular}{|c|c|c|c|}
\hline \multicolumn{2}{|l|}{ Insourcing } & \multicolumn{2}{|l|}{ Outsourcing } \\
\hline Root Causes & ARP & Root Causes & ARP \\
\hline Less in process business training & 69,98 & Less in process business training & 59.04 \\
\hline Culture internalization not intensive & 68,45 & Less in knowledge sharing between units & 56.70 \\
\hline Inappropriate monitoring method & 60,93 & CMMS data input manually & 36.72 \\
\hline Less in knowledge sharing between units & 56,70 & Lack of Communication between some department & 23.14 \\
\hline Less in the accuracy of evaluation & 38,21 & Less in the racy of evaluation & 16.95 \\
\hline CMMS data input manually & 36,72 & Inappropriate monitoring method & 15.09 \\
\hline Less in job description detail & 20,51 & Un intensive Culture internalization & 14.31 \\
\hline Incomplete work instructions & 19,44 & Un intensive management walk around & 10.13 \\
\hline Un intensive management walk around & 17,82 & Less in the involvement of other fields & 9.00 \\
\hline Document in hardcopy & 11,79 & Review and evaluation process business training not done & 8.48 \\
\hline Less in sharing knowledge & 11,40 & Less in sharing knowledge & 6.84 \\
\hline Lack of consulting from superiors & 11,33 & Reference not updated & 6.72 \\
\hline Less in field practice & 11,00 & Not all technical data covered in the CMMS & 5.88 \\
\hline Un intensive Coaching and mentoring & 10,88 & Less in job description detail & 5.88 \\
\hline Review and evaluation business process was not done & 9,75 & & \\
\hline
\end{tabular}

follow same problem and root cause that already defined [9]. Hypothesis from earlier data was with outsourcing the problem and root cause in insourcing not exist on PM implementation process, furthermore, if there is finding new root cause, the proactive strategy will be defined in order to improve outsourcing PM process effectively.

\section{LITERATURE REVIEW}

\section{A. Preventive Maintenance}

$\mathrm{PM}$ is a series of maintenance work performed at frequencies determined by the passage of time (time interval), production quantity, cycle, machines operating hours, mileage, with advantages to extend the life of the asset and act as detection critical wear and failure intending. Preventive and predictive maintenance with all of its requirements becomes an effective action that contributes to reducing equipment failure at an early phase of operation until the end of its life [22][23].

\section{B. Outsourcing}

Outsourcing practices have varied considerably ranging from externalizing support activities to some core processes, from activities that are primarily service-based to productive processes, as in the case of modular production and many studies take the idea that the adoption of outsourcing strategies can be associated with increasing pressure on management to gain greater efficiency, effectiveness and productivity through strategies such as restructuring, streamlining, and reengineering activities [12][13]. General conditions of maintenance outsourcing regarding data collection issues are not handled properly in most outsourcing maintenance, another side effective maintenance management requires proper data management, data collection and analysis for decision making and thus requires the right framework, thus when maintenance is outsourced will not cause new problems and challenge [13].

\section{House of Risk (HOR), CIMOSA and SCRIS.}

House of Risk (HOR) method is a proactive risk management method that focuses on preventive mitigation, in which the risk agent identified as the cause of the risk event can be managed with effective productive steps. It aims to reduce the possibility of risk agents so that risk events do not appear or decrease [24]. HOR method approach divided into two phases: HOR1 outputs was calculation of Aggregate Risk Potential (ARP) which its formula was sum product of severity $(\mathrm{S})$, occurrence $(\mathrm{O})$ and correlation value between problem and root causes (R) and HOR-2 calculation resulted in providing an effective level of the solution strategy that has considered difficulty level of implementation. CIMOSA expresses the inherent role task in a company process with describing as a sequence of activities that require input to obtain results and require resources for actions to be undertaken [25][26][27], and [28]. SCRIS will be used as an arrangement of problem and root causes base on hierarchical structure, which represents time, location and risk owners and causal structure, representing the source and the impact [29].

\section{METHODOLOGY}

This research was divided into 4 stages, which are gathering data Severity $(\mathrm{S})$ and Occurrence $(\mathrm{O})$ from observation with root cause already defined [9] then analysis phase with HOR-1 and HOR-2 and select appropriate proactive strategy solution. Data gathering in this research by exploring CMMS data, manual document collecting, site direct observation, interview, and Forum Group Discussion (FGD).

\section{RESULT}

The data of equipment maintenance history was took from CMMS then analyzed the comparison of PM interval and the MTBF. The value of comparison for insourcing in compressor system is 5.4:1 and for outsourcing in conveyor system is $13: 1$. The calculation used data from the whole system at the compressor and conveyor to maintain the objectivity of calculation.

Severity level observed directly at each case with the consideration that business process flow in outsourcing and insourcing has the same step and same responsibilities on each stage thus the impact of the problem that occurs will be same, the difference was only in a department that executes PM.

Occurrence observation did 5 times at each root cause in each case and take the result from the amount of recording. Occurrence value was obtained from the questionnaire, direct observation and interview with 42 people in maintenance planner, engineering, maintenance and outsourcing for coal handling facility department. The observation to measure occurrence did in different office and site area, with random person and location especially in site area did at the area of insourcing and outsourcing. 
TABLE 3.

PRIORITY PROACTIVE STRATEGY RANKING

\begin{tabular}{lllc}
\hline \multicolumn{1}{c}{ Insourcing } & \multicolumn{1}{c}{ Outsourcing } \\
\hline \multicolumn{1}{c}{ Proactive Strategy } & ETD $k$ & \multicolumn{1}{c}{ Proactive Strategy } & ETD $k$ \\
Optimization of the transformation agent & 699.28 & Culture and asset management induction & 308.88 \\
Optimization of walk around & 585.73 & Site facility walk around & 249.78 \\
The corporate PM monitoring system & 409.95 & Involved in outsourcing meeting work & 186.95 \\
In-house refresh training PM \& governance & 389.74 & The corporate PM monitoring system & 136.92 \\
CoP Optimization & 315.35 & The Corporate PM Standard & 104.17 \\
The Corporate PM Standard & 240.25 & CoP Optimization & 97.10 \\
CM/PM integrated application & 232.59 & CM/PM integrated application & 65.33 \\
Corporate PM PGD and database creation & 174.49 & Knowledge sharing forum with others & 63.55 \\
\hline \hline
\end{tabular}

HOR-1 resulted in ARP value that calculates from sum product of severity, occurrence and correlation value between the problem and the root causes. The correlation value used from previous research that already conducted in the same power generation site. All calculation was performed in HOR-1 table and continued with ARP Pareto analysis to obtain ARP ranking in purpose to get selected root cause for proactive strategy development. Proactive solution strategy was obtained from root cause that covers $80 \%$ of total cumulative ARP Pareto for both sourcing scheme with s suggestion that this amount of root cause will be disturbing on almost all PM implementation process. The Pareto selected ARP value from both is displayed in Table 1. The selected root cause from cumulative ARP in both is displayed in Table 2 with the value of calculating ARP.

HOR-2 analysis required a value on the relationship between proactive strategy and its strength to solve selected root causes, which correlation value between root cause and proactive strategy same as in HOR-1. It value determination involved 11 expert people in asset management in Forum Group Discussion (FGD) to obtain objective value. HOR-2 calculation refers to Eq.2 and Eq.3 resulted in providing an effective level of the solution strategy that had considering difficulty level of performing an action.

At the end of the HOR process, proactive solution strategy was and proactive strategy solution that already calculated effectiveness to solve the problem and difficulty on performing an action is displayed in Table 3 .

It can be seen that effectiveness to difficulty ratio for the outsourcing was lower than insourcing since the difficulty of performing action value was same between both programs, it means the program that conducted in insourcing will not give same effectiveness in outsourcing scheme.

\section{DISCUSSION AND IMPLICATION}

CMMS data analysis shows that PM with outsourcing gives higher compliance to WCM standard [10]. After root causes identification from ARP, the employee in both scheme look didn't have enough perspective on the philosophy of PM which as a part of TPM [3][5], and [6], 6]. In the outsourcing scheme there was minor appearance of soft skill issue in the highest ARP root cause [15][16][17][18][19][20], and [21], and there is no issue about task instruction and description for PM work, work experience of personnel in outsourcing [1][2][3][5][6], and [7]. This has become an indication that in outsourcing scheme most of the personnel understanding the performance indicator to keep customer satisfaction on the highest level [11]. Coaching and mentoring for the personnel of outsourcing look like smoothly conducted.
Management role needs to concern in site observation and interaction supported with suitable data management for better monitoring and evaluation in both schemes but management need more accurate data to calculate the performance of outsourcing maintenance [4][28], and [29]. The implication is the company must prepare the update of key performance indicator, intensive coaching and mentoring for insourcing PM and prepare budgeting for the training of business process governance.

\section{CONCLUSION}

In the outsourcing scheme, they have higher consistency in performing the soft skill on PM implementation [5][8], and [9]. The proactive strategy for the insourcing and outsourcing was at the same method [8], but in outsourcing need less effort to improve PM effectiveness because basically they already performed requirement in obtaining process performance indicator [3][5][6][9], and [12]. Optimization of the transformation agent is expected to create awareness in both scheme [17][18], and [19] but the agent does not need to involve in internalization of corporate culture on the outsourcing department, only give some induction in purposes it must be aligned with. Walk around need to be conducted in both scheme but in outsourcing the aim is directed to maintain the engagement [7][20], and [21]. An application system with better data management needed for both scheme but in the outsourcing need more to get best performance in PM implementation [3][4][6][9], and [13]. The problem of soft skills still dominates problem root causes in PM works for insourcing and outsourcing scheme and this can be solved with concern in conducting corporate culture, support with respectively management role and providing appropriate monitoring and evaluation system.

\section{REFERENCES}

[1] A. Tsang, "Strategic Dimensions of Maintenance Management," J. Qual. Maint. Eng., vol. 8, no. 1, pp. 7-39, 2002.

[2] J. Campbell, A. Jardine, and J. McGlynn, Asset Management Excellence - Optimizing Equipment Life-Cycle Decisions. Florida: Taylor \& Francis Group, 2011.

[3] L. Hinggins, R. Mobley, and R. Smith, Maintenance Engineering Handbook. New York: Mc Graw - Hill Inc, 2002.

[4] M. Wienker, K. Henderson, and J. Volkerts, "The Computerized Maintenance Management System An essential Tool for World Class Maintenance, 3rd International Symposium on Innovation and Technology in the Phosphate Industry," Procedia Eng., vol. 138, pp. 413-420, 2016.

[5] M. Ben-Daya, S. Duffuaa, R. A., J. Knezevic, and D. Ait-Kadi, Handbook of Maintenance and Engineering. London: Springer-Verlag, 2009.

[6] J. Levitt, Maintenance Management. New York: Industrial Press, 2009.

[7] P. Muchiri, L. Pintelon, H. Martin, and A. De Meyer, "Empirical analysis of maintenance performance measurement in Belgian," Int. J. Prod. Res., vol. 48, no. 20, 
pp. 5905-5924, 2009.

[8] E. Sari, M. Shaharoun, A. Ma'aram, and A. Yazid, "Sustainable Maintenance Performance Measures: a pilot survey in Malaysian Automotive Companies," Procedia CIRP 26, pp. $443-448,2015$.

[9] B. Siswanto, A. Sudiarno, and P. Karningsih, "Improvement of Preventive Maintenance Process Implementation Effectiveness with House of Risk (HOR) Method Approach," in ITES International Conference, 2018.

[10] S. Imam, J. Raza, and R. Chandima Ratnayake, "World Class Maintenance (WCM): Measurable indicators creating Opportunities for the Norwegian Oil and Gas industry," in Conference Paper, 2013.

[11] U. Dombrowski and M. T., "Lean Leadership - 15 Rules for a sustainable Lean Implementation," in Proceedings of the 47th CIRP Conference on Manufacturing Systems, Procedia CIRP 17, 2014, pp. $565-570$.

[12] L. Giustiniano and G. Clarioni, "The Impact of Outsourcing on Business Performance: An Empirical Analysis," J. Mod. Account. Audit., vol. 9, no. 2, pp. 153-168, 2013.

[13] D. Murthy, M. Karim, and A. Ahmadi, "Data management in Maintenance Outsourcing," Reliab. Eng. Syst. Saf., vol. 142, pp. 100-110, 2015.

[14] H. Meier, H. Lagemann, F. Morlock, and C. Rathmann, "Key Performance Indicators for Assessing the Planning and Delivery of Industrial Services," in 2nd International Through-life Engineering Services Conference, Procedia CIRP 11, 2013, pp. 99-104

[15] W. Ariratana, S. Sirisookslip, and T. Ngang, "Development of Leadership Soft Skills Among Educational," in Procedia Social and Behavioral Sciences, 2015, pp. 331 - 336.

[16] K. Attakorn, T. Tayut, and S. Pisitthawat, K. and Kanokorn, "Soft Skills of New Teachers in the Secondary Schools of Khon Kaen Secondary Educational Service Area 25, Thailand," in International Conference on Education \& Educational Psychology 2013 (ICEEPSY 2013), 2014.

[17] W. Koot, “Anthropology of - Organizational Culture," Encycl. Soc. Behav. Sci., pp. 10934-10938, 2001.

[18] M. Hitka, M. Vetráková, Z. Balážová, and Z. Danihelová, "Corporate Culture as a Tool for Competitiveness
Improvement," in Business Economics and Management 2015 Conference, 2015, pp. $27-34$.

[19] I. Ibrahim, A. Boerhannoeddin, and B. Kayode, "Organizational Culture and Development: Testing the Structural Path of Factors Affecting Employees' Work Performance in an Organization," Asia Pacific Manag. Rev., vol. 22, pp. 104-111, 2017.

[20] A. Tucker and S. A., "The Effectiveness of Management-ByWalking- Around: A Randomized Field Study," Agency Healthc. Res. Qual. RO1 HSO13920, 2013.

[21] U. Dombrowski and M. T., "Lean Leadership fundamental principles and their application," in Forty-Sixth CIRP Conference on Manufacturing Systems, 2013, pp. 569 - 574.

[22] P. Murthy, A. Atrens, and E. J., "Strategic maintenance management," J. Qual. Maint. Eng., vol. 8, no. 4, pp. 287-305, 2002.

[23] J. Coetzee, "A Holistic Approach to The Maintenance "Problem“," J. Qual. Maint. Eng., vol. 6, no. 3, pp. 138-164, 1999.

[24] I. Pujawan and L. Geraldin, "House of Risk: A Model for Proactive Supply Chain Risk Management," Bussiness Process Manag. J., vol. 15, no. 2, pp. 963-967, 2009.

[25] K. Kosanke, F. Vernadat, and M. Zelm, "Means to enable Enterprise Interoperation: CIMOSA Object Capability Profiles and CIMOSA Collaboration View," in Proceedings of the 19th World Congress The International Federation of Automatic Control, 2014, pp. 24-29.

[26] B. Heulluy and F. Vernadat, "The CIMOSA Enterprise Modelling Ontology," IFAC Manuf. Syst. Model. Manag. Control, 1997.

[27] K. Kosanke and V. F., "CIMOSA and GERAM Standardisation in Enterprise Engineering," IFAC Inf. Control Manuf., 1998.

[28] G. Berio and F. Vernadat, "Enterprise modelling with CIMOSA: functional and organizational aspects," Prod. Plan. Control, vol. 12, no. 2, pp. 128-136, 2001.

[29] P. Karningsih and B. Kayis, "SCRIS: A Knowledge-Based System Tool for Assisting Manufacturing Organizations in Identifying Supply Chain Risks," J. Manuf. Technol. Manag. vol. 23, no. 7, pp. 834-852, 2011. 